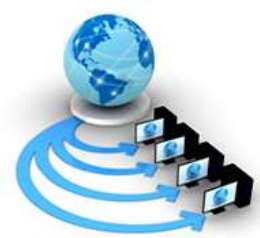

Volume 10, No. 2, March-April 2019

International Journal of Advanced Research in Computer Science

RESEARCH PAPER

Available Online at www.ijarcs.info

\title{
ELECTRONIC DOCUMENT MANAGEMENT SYSTEM IMPLEMENTING INTERNET OF THINGS (IOT)
}

\author{
Analyn R. Mendoza \\ College of Computer Studies \\ TrimexColleges, Biñan, Laguna, Philippines
}

Henriette Mae Castillo

College of Business \& Accountancy

TrimexColleges, Biñan, Laguna, Philippines

\author{
Cristina Alvarez \\ College of Business \& Accountancy \\ TrimexColleges, Biñan, Laguna, Philippines \\ MaricelManongsong \\ College of Business \& Accountancy \\ TrimexColleges, Biñan, Laguna, Philippines
}

\author{
Andromeda Santiago \\ College of Business \& Accountancy \\ TrimexColleges, Biñan, Laguna, Philippines
}

\begin{abstract}
The system that we're about to improve will give remedies on the troubles that our customer encountered. Shifting on Electronic Document Management System Implementing Internet of Things (Iot) will gather benefits and ease to a business technique such as decreasing working hours, storage space and this will expand the efficiency of the business enterprise plant's operation and aiming for paperless documentation that will guide the Human Resource (HR) and Quality Assurance (QA) Departments. All archives about product quality, nonconformity reports and employee's data compiled in the gadget with the aid of the usage of Electronic Document Management System Implementing Internet of Things (Iot). We gathered the data, summarized, assigned approved personnel, uploaded a file for viewing, modifying and authorization. Prevents the information redundancy, loss of data, cope up with customer's documentation request in a limited time, the file sharing and organized facts base for history monitoring and got here up with digital filing.
\end{abstract}

Keywords: Electronic,Document, Management System, Emplementing, Iot

\section{INTRODUCTION}

Today the technological know-how is at the best possible top of popularity; improvements occur as time passes and making all things possible thru the assist of the structures technology. The enterprise is the primary consumer of today's technology, via the use of technological know-how companies earn. Most, agencies started in a manual submitting of record, and it includes our client. The products are generally exported in one-of-a-kind nations like Japan, Spain, Germany and more. The company's key to success is with the aid of producing an excessive quality, unique style and enthralling seem to be of products with the assistance of expert specialists behind to make it happen.

Our client is the usage of a Microsoft Office Application System to date, in managing their record management system. When a customer order is placed, they will create a standard document report for each product. However, the management has to put a great deal effort into securing those files. It can be effortlessly damaged via fire, bugs or even natural mess ups like flood and earthquake and maintaining a tab on records monitoring will consume long hours. Thus, the accuracy of file searching is at risk. In some cases, the verification of preceding order details is necessary. Eventually, this system will take time to complete.
There is a situation that flawed worksheet files have been transferred to the manufacturing department that reason more than one product claims / reject. Another state of affairs is about the failure to comply manner and work instructions filethose consequences to $40 \%$ of product defects.

When the business reaches the very best stage of demands from their customers, this manually operated machine will no longer be useful, in this state of affairs the client is going through the same problem and claims. Due to its market demands, agencies will continually discover upgrades to upgrade their contemporary device with a common intention to attain its product excellent and consumer satisfaction.

The system that we're about to advance will provide redress on the troubles that our customer encountered. Shifting on Electronic Document Management System Implementing Internet of Things (Iot) will gather blessings and ease to commercial enterprise technique such as lowering working hours, storage area and this will expand the efficiency of the employer plant's operation.

To strengthen and put into effect our study .These will supply report sharing, report privacy, blanketed editing, file revisions, electronic mail, and two SMS notifications. All referred to essential points and records are stored in the system. This will save time when creating, revising or even retrieving data from the database. Interfaces plan are userfriendly as it can be operated with the aid of the serving 
department and the features will be displayed in a natural surroundings view.

\section{DESIGN OF THE STUDY}

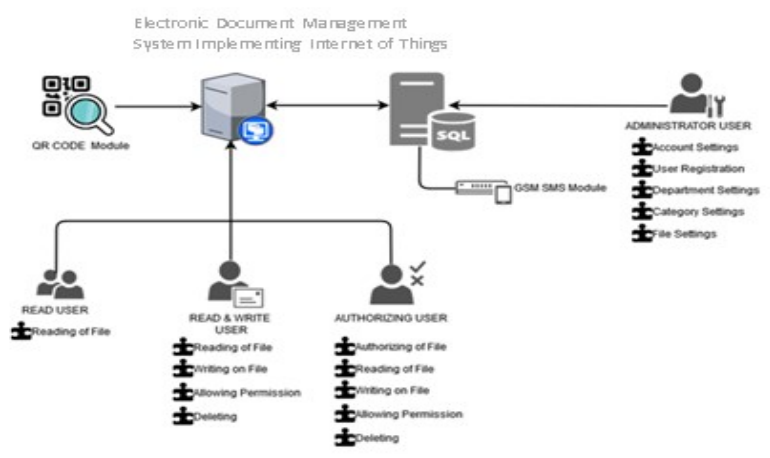

Figure 1: System Architecture

Figure 1 shows the different component of the Web Application System. Currently, barangay has no established system in processing request and giving notification to its residents. On the proposed project, the user will be responsible for browsing the website, requesting documents, make an appointment to barangay and receive SMS notifications from barangay. Admin will be responsible for updating websites, accepting and declining request, notify residents, and updating barangay master list.

\subsection{Network Design Infrastructure}

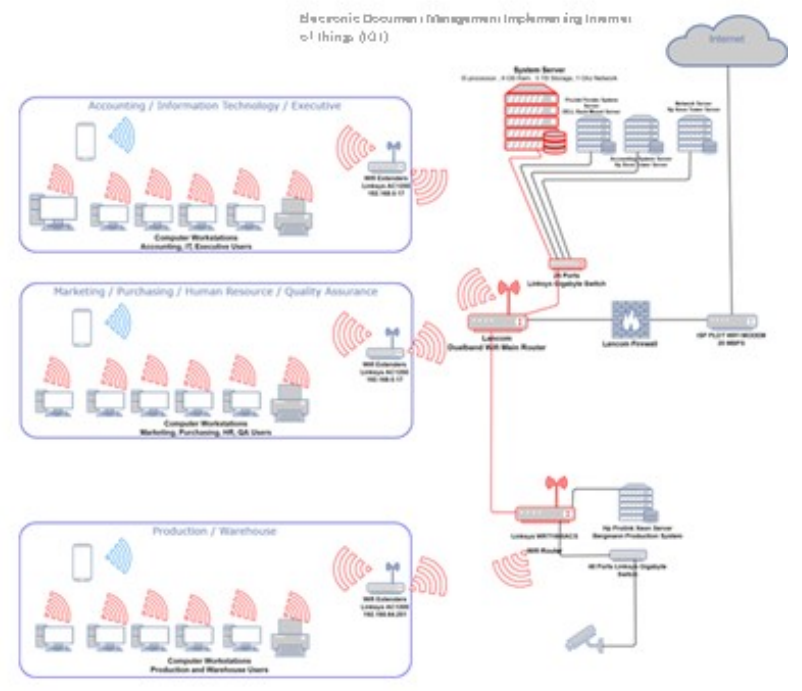

Figure 2: Network Design Infrastructure

There is whole of 5 servers on the network, one of this machine server is for The Electronic Document Management System Implementing Internet of Things (IOT) that will be used for Document Management System from time - time user, gadgets are totally well matched in this gadget some of these are the Computer Desktop, Laptop with Firefox browsers for widespread use. The specification of the said devices is not decreased than Dual core processors and 4 Gigabytes of Ram and at least $100 \mathrm{Mbps}$ to the $1 \mathrm{~GB}$ velocity of Network.

\section{LITERATURE SURVEY}

Towards a paperless medical physics residency management system

As mentioned by way of Schubert (2014), documentation is a required aspect of a residency program, however can be challenging to gather and disseminate, resulting in minimal utilization via residents and faculty. The purpose of this work is to adapt a commercially-available Web-based scientific residency administration device to enhance the getting to know trip by way of effectively distributing software information, documenting resident activities, and presenting time-honored monitoring and well-timed remarks of resident progress. To distribute application information, program necessities and rotation readings had been uploaded. An educational convention calendar was created with associated archives and attendance information added. To report resident progress, requirements for over 37 one of a kind clinical techniques were added, for which the resident logged the complete quantity of methods performed.

Progress reports have been created and mechanically distributed. To furnish comments to the resident, an extensive electronic comparison system used to be created. Results are shown for the initial 21 months of software existence, consisting of a single resident for the first 12 months and two residents for the subsequent 9 months. The device recorded that a hundred thirty files had been uploaded and one hundred percent of required documents had been downloaded with the aid of the resident. In total, 385 academic conferences and conferences were offered, of which the residents attended $95 \%$.

The second-year and first-year residents logged 1030 and 522 clinical procedures, respectively. The residents submitted a complete of 116 popularity reports detailing weekly activities, one hundred percent of which had been reviewed with the aid of college inside an common of 11.3 days. A complete of 65 evaluations of the residents had been submitted. The residents reviewed a hundred percent of respective evaluations inside an average of 1.5 days. We have correctly incorporated a paperless, Web-based management gadget in a scientific physics residency program. A sturdy digital documentation gadget has been implemented, which has played a central function in improving the education experience.

http://onlinelibrary.wiley.com/doi/10.1120/jacmp.v15i6.486 6/fullShort Message Services (SMS)

\section{Document E-Tracker: A Panacea for Efficient Internal Document Management System in Kaduna Polytechnic}

As State Hamis\&Aju (2015), guide archives have emerged as of large extent due to make bigger in the use of laptop for working procedure on each day basis. two Many groups nowadays manually tune statistics or they do now not put in place any tracking process, as a result, looking for file consumes time therefore waste of productivity. Handling of high-priority file in an enterprise ought to be tragic if there is marginal carelessness and incompetency. 
Kaduna Polytechnic is a particularly giant institution with a centrally managed administration however operational things to do allot amongst 5 exceptional academic colleges that are geographically unfold inside the town In order to improve the movement of file amongst within this widely disbursed administrative setup of Kaduna Polytechnic it is integral to have and efficient report monitoring system. A answer system recognized as E-Track used to be developed for the monitoring of documents' motion amongst tutorial Colleges in Kaduna Polytechnic. Open source tools such as PHP and MySQL had been used to develop E-Track inside Windows environment.

http://www.atbuftejoste.com/index.php/joste/article/view/95 Barangay System

File management system and collaboration service and integration capabilities with third party applications

As stated through Sam Ghods, Florian Jourdan and Aaron Levie (2016), a gadget and method for presenting a file management service for collaboration is disclosed. The technique for supplying a file administration carrier for collaboration, which may additionally be carried out on a system, includes, for example, imparting a consumer thru which a user accesses a file thru the file management service, further providing, by using the file management provider via the client, the consumer with collaboration functionality of the file with other users, and/or controlling editing of the file by using different users based on whether or not it is designated as being shared by means of the user. In one embodiment, the file administration provider similarly enables integration of a third-party provider with the file management provider and the third-party service is accessible for use with the file by the file management service.

https://www.google.com/patents/US9519526

\section{Electronic Document Management System}

As stated through Elin del Rosario, Julian del Rosario, Mirro Nieva, Tiara Tan and Marivic Tangkeko (2016). The predominant hassle that stood out from all the different troubles gathered whilst growing the system used to be time. The proponents performed interviews with the different people involved to acquire relevant information and remarks to assist resolve the problem. Based on the facts gathered, the proponents got here up to a solution which there will be one channel the place the students and school can talk about their thesis. Through this system, the proponents have been able to maximize the time of each the students and college when dealing with their thesis. The time saved can be used for other work that may additionally contribute to the productivity of faculty and students.

Electronic report management device (EDMS) helps in managing archives electronically (Minnesota Historical Society, 2012). Moreover, EDMS provides security of statistics while it still lets in handy get right of entry to of the customers to the electronic record (Oakleigh Consulting Ltd, 2007). The method of EDMS has to do with capturing, storing, indexing and retrieval. It improves the gaining access to of records via the users of the employer whereby they can easily search and retrieve the documents needed.
Also, there will be security in such a way that the solely licensed users are allowed to access the precise documents. (ND Information Technology Department, 2014) http://www.dlsu.edu.ph/conferences/dlsu-research-congressproceedings/2016/HCT/HCT-II01.pdf

\section{QMBTIS Case Management System with EDMS}

As mentioned with the aid of Mark Cribe, Garry De Leon, Adrian Libiran, Tyrone Lim and Renato Jose Molano (2016), two law corporations are responsible for creating and receiving distinct kinds of information and statistics used in the exceptional instances of their clients. Given the amount of information, documents and statistics being managed by regulation firms, troubles occur in terms of the inability to exact manipulate the special case documents. Some of the problems encompass misplaced or loss of documents; situation in sharing of case files; and sluggish retrieval of case documents.

Through the use of Information and Communication Technologies (ICT), a well-designed case administration device helps law corporations in addressing these problems and aids in the fine performance of their exclusive processes. Through the learn about and integration of a case management system, the gadget serves as a answer to supply an environment friendly avenue of managing and organizing the different cases treated by means of the regulation firm. The purpose of this find out about is to discuss and current the answer of a case management system built-in into the regulation firm, mainly for the approaches of Quiason Makalintal Barot Torres Ibarra and Sison (QMBTIS).

The case administration device incorporates eight exclusive modules which are case administration and tracking, scheduling \& calendaring, dockets management, digitizer, digital file administration gadget (EDMS) component, proof management, report generation and mobile accessibility. These modules had been designed considering the workflow of QMBTIS in dealing with their legal cases. It is hoped that via this study, regulation corporations will further see fee in integration of Information and Communication Technologies (ICT), in particular a case management gadget in order to aid with the company's business processes. http://www.dlsu.edu.ph/conferences/dlsu-research-congressproceedings/2016/HCT/HCT-I04.pdf 


\subsection{Flowchart}

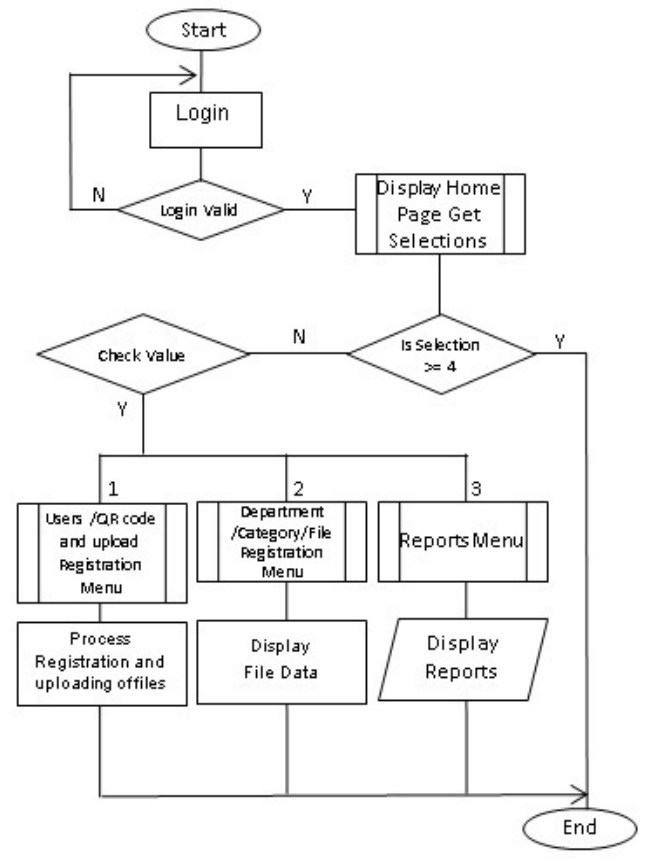

Figure 3:Administrator

The administrator will log in to the web page.

If you go to the User, QR code login and upload, the consumer account can be registered with the QR code photographs also include the additional files. At this Department, updating and creating: category, and file edit can be found. The time to time get admission to log, and file list export reviews can also be generated base on your chosen names.

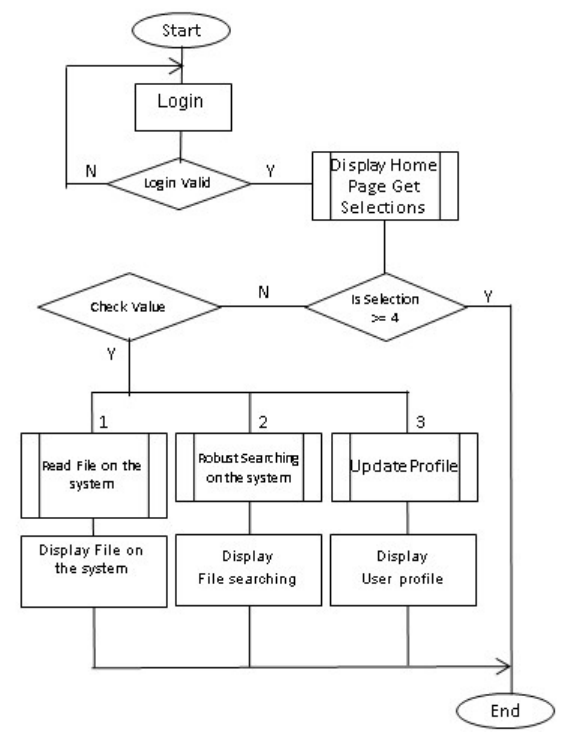

Figure 4: User

The User will $\log$ in to the net page. If you go to the Reading of file, you can study archives involve to you in the system.

If you Search a file, the system will show the actual data that is you searching for on the file list on the network. Update profile, you can change right here your Password, Email, Phone number, and Qr code.

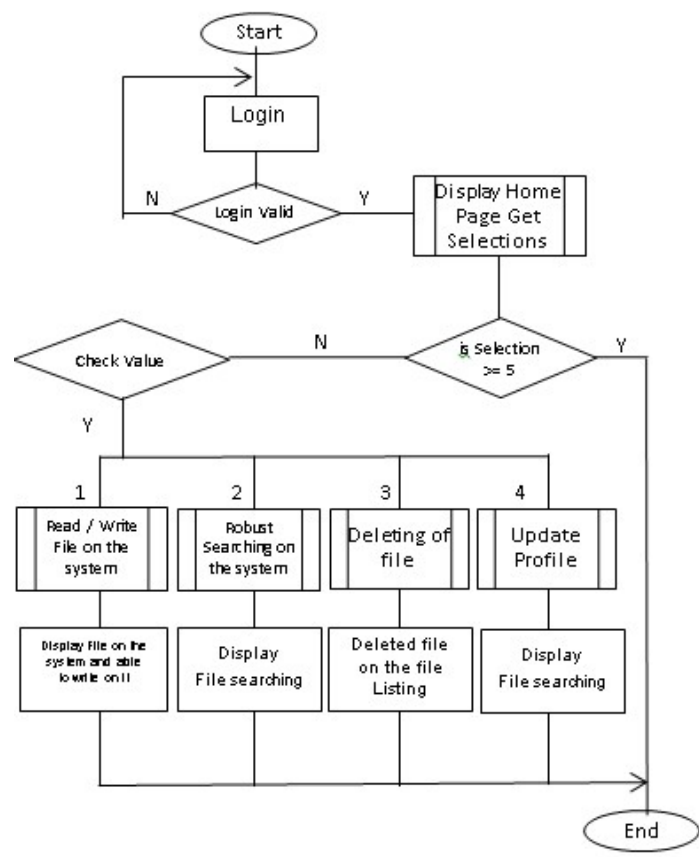

Figure 5: Approving User

The User will log in to the web page.

If you go to the Reading of file, you can read data contained to you, and you can also "check out" or write on the data assigned to you in the system.

If you Search a file, the gadget will show the actual data that is you looking for on the file listing on the network.

If you delete a file assigned to you, you will not be capable of seeing it anymore in the gadget file listing. Update profile, you can trade right here your Password, Email, Phone number, and Qr code.

\section{RESULTS AND DISCUSSION}

Electronic Document Management System Implementing Internet of Things (IOT)

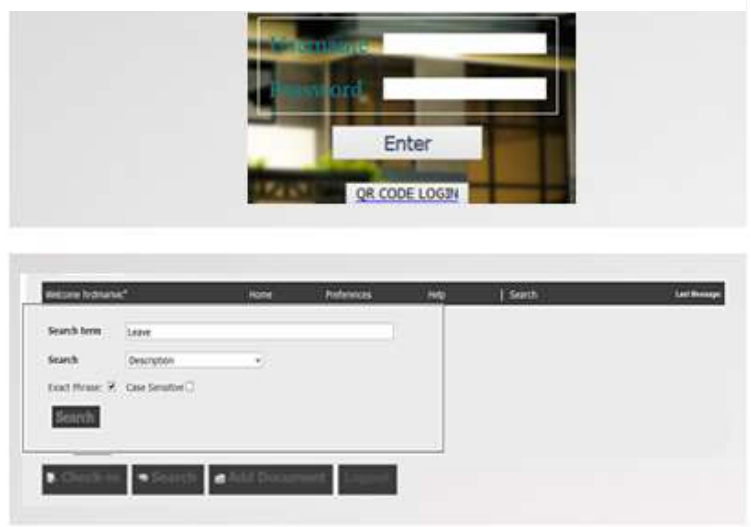

Figure 6: The features of Electronic Document Management System Implementing Internet of Things (Iot) 


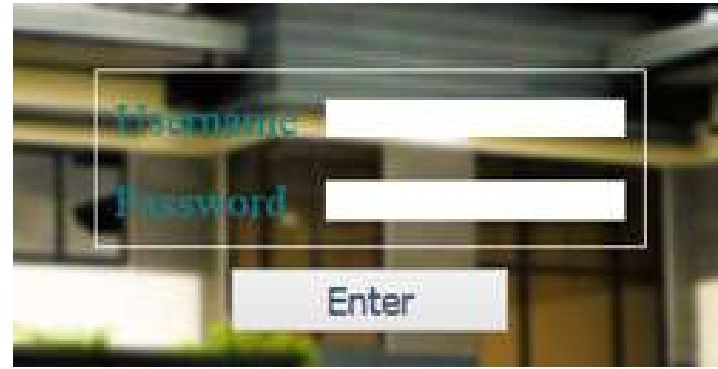

Figure 7: Log-in of username and password

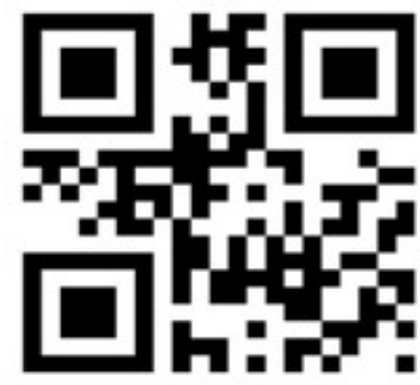

Figure 8: QR Code

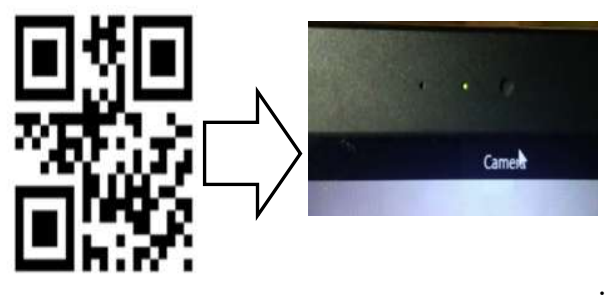

Figure 9:Scanning QR Code

Will scan and accept QR code uing integrated Camera.

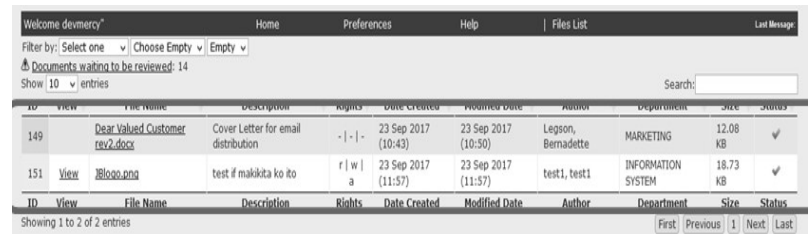

Figure 10: Posted File

A module that will store scanned documents and can easily retrieve by a search module.

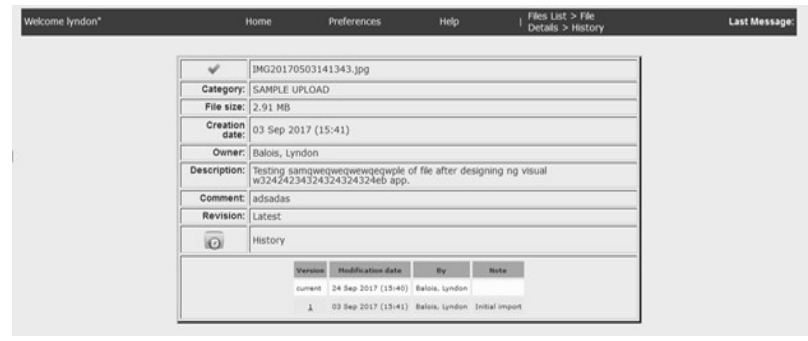

Figure 11: File Revisions
A module that will monitor documents revision.

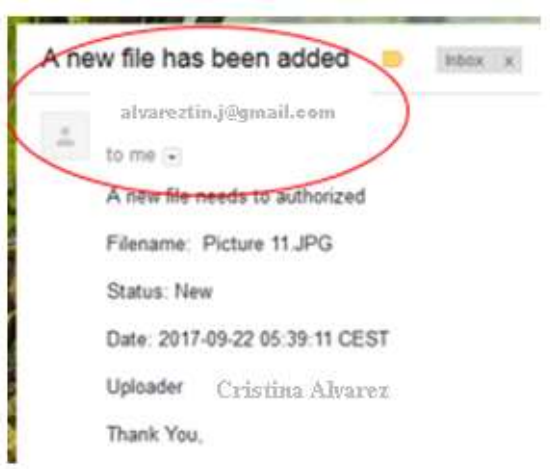

Figure 12: Email Automated Notifications

A module that will notify the uploading of documents through email.

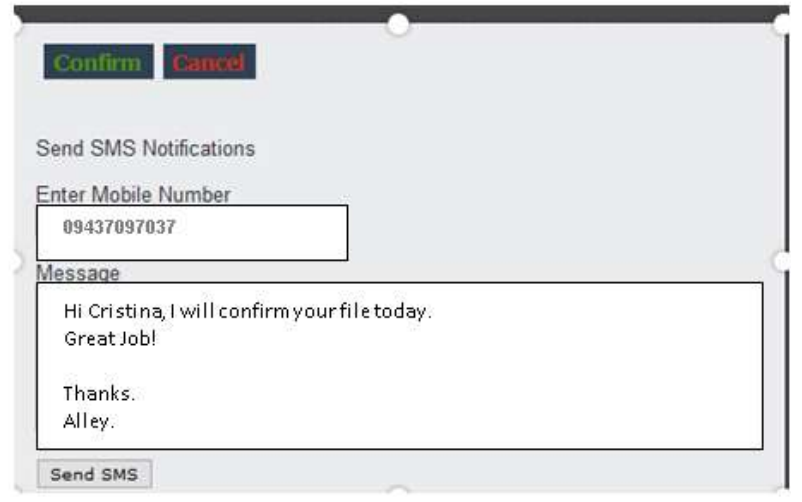

Figure 13: SMS Messaging

A module that will notify the approval of documents via sending text message using GSM component.

\section{CONCLUSIONSAND RECOMMENDATIONS}

\section{Conclusions:}

Based on the study learns about conducted by way of proponents and feedbacks acquired from the clients here are the consequences gathered:

The device received fantastic feedback on the synchronization of facts between the QA Department and Warehouse archives of documents. The workload of DCC personnel has been eradicated with about $80 \%$ on a compilation of documents. The record monitoring for revision of a file is at reached whenever they need it.Confidentiality of every department was secured by using offering each due to the fact of permission safety set in the system.

\section{Recommendations:}

The researcher of the study would like to recommend the following:

Develop the new features that will suit the demand of clients in the future. 


\section{REFERENCES}

[1] Schubert (2014)"Towards a paperless medical physics residency management system," Retrieve

fromhttp://onlinelibrary.wiley.com/doi/10.1120/jacmp.v1 5i6.4866/fullShort Message Services (SMS)

[2] Hamis\&Aju (2015)“Document E-Tracker: A Panacea for Efficient Internal Document Management System in Kaduna Polytechnic," Retrieved from http://www.atbuftejoste.com/index.

Php/joste/article/view/95Barangay System

[3] Sam Ghods, Florian Jourdan and Aaron Levie (2016)

"File management system and collaboration service and integration capabilities with third party applications,"Retrieved from.
https://www.google.com/patents/US9519526

[4] ElinDel Rosario, Julian Del Rosario, MirroNieva, Tiara Tan and MarivicTangkeko (2016) "Electronic Document Management System," Retrieve from http://www.dlsu.edu.ph/conferences/

Dlsu-research-congressproceedings/2016/HCT/ HCT-II01.pdf.

[5] Mark Cribe, Garry De Leon, Adrian Libiran, Tyrone Lim and Renato Jose Molano (2016) "QMBTIS Case Management System with EDMS,'

Retrievedfrom.http://www.dlsu.edu.ph/confer Ences/dlsu-research-congress-proceedings/2016/ HCT/HCT-I04.pdf. 